\title{
Lumbar Sagittal Alignment May Be a Good Predictor for the Lumbar Spine Degeneration
}

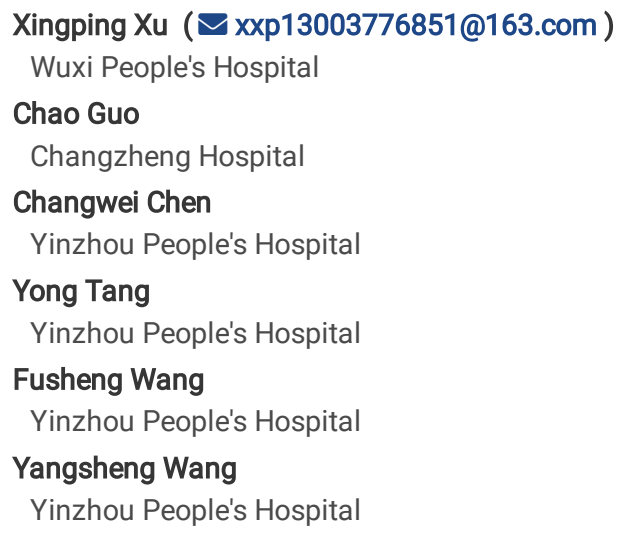

\section{Research article}

Keywords: lumbar sagittal alignment, Modicchange, Endplatedefect, clinical outcomes

Posted Date: August 2nd, 2020

DOI: https://doi.org/10.21203/rs.3.rs-50584/v1

License: (c) (i) This work is licensed under a Creative Commons Attribution 4.0 International License. Read Full License 


\section{Abstract}

Background

Increasing attention has been focused on (modic changes and end plate defect) MC\&ED as a potential role in the etiopathogenesis of lumbar degeneration. The precise mechanism leading to progression of MC\&ED is lacking. Some scholars thought lumbar sagittal alignment might be a key influence factor, but without enough clinical evidence. Hence, we investigated how lumbar sagittal alignment influences MC\&ED.

\section{Methods}

Ninety-six asymptomatic or symptomatic patients with Modic changes or end plate defect were retrospectively recruited in this study from August 2016 to December 2018. MC\&ED were observed in 76 patients and not observed in 20 patients, representing two groups for comparison. The lumbar sagittal parameters were measured, including lumbar lordosis (LL), pelvic incidence (PI), sacral slope (SS), and pelvic tilt (PT).

The lumbar lordosis index(LLI) and idea LL were then calculated. Clinical outcomes were assessed using a visual analog scale(VAS) and an Oswestry Disability Index (ODI) before and after an operation.

Results

There were no significant difference in the distribution of demographic and baseline clinical variables between both groups. Mean age and BMI showed significant difference between both groups $(P<0.05)$. There were significant correlations between LL, LLI, Loss of LL, and Level $1(r=0.281,0.230$, and $0.284, P<0.05)$ Also, PI, PT were significantly correlated with Level $4(r=0.249,0.202, P<0.05)$. Compared with presurgery scores, an improvement was seen in postoperative VAS and ODI scores $(P<0.05)$. Further, the postoperative scores at 24 months in the without Modic or end plate defect group showed greater improvements compared with the with Modic or endplate defect group $(P<0.05)$.

Conclusion

This analysis indicated that maintaining lumbar sagittal alignment was related to a lower risk of Modic changes in patients with the spinal degenerative disease. The lumbar sagittal alignment might be a factor that influenced the posterior inclination of the pelvis in symptomatic lumbar disease.

\section{Background}

Degenerative pathologies of the lumbar spine, including Modic changes and endplate defect, are common in the elderly population[1]. Modic changes (MCs) are shown as MRI signal variation in vertebral and subchondral bone marrow adjacent to the end plate[2]. MCs are assigned into three subtypes:

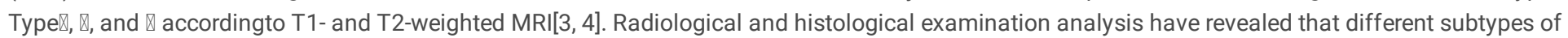
MCs respectively displayed inflammatory responses, fatty marrow, and subchondral bone sclerosis. MCs are frequently observed in pathological structure changes like disc degeneration, disc herniation, and endplate defect [5-7]. A recent study demonstrated that there is an association between endplate defect and disc degeneration in a large-scale, population-based study. Several theories have been proposed with respect to the etiology of MCs and end plate defect. Recently, clinical studies have paid attention to endplate defects as acting as a concomitant role in the etiopathogenesis of MCs[8]. Korreset al demonstrated that the lumbar spine act as a role in maintaining the upright posture and form the body trunk shape via maintaining proper sagittal alignment[9]. In fact, sagittal alignment has been related to various lumbar conditions. There are several reports demonstrating that sagittal malalignment contributes to lumbar disc degeneration. Buckland et al reported that worsening sagittal malalignment was associated with lumbar stenosis on stereo-radiographs[10]. Ogura et al showed that sagittal spinopelvic alignment as a significant impact on health-related quality of life and clinical outcomes after surgery[11]. Recent studies have demonstrated that patients with lumbar malalignment are frequently presented with sympathetic symptoms such as low back pain.

The motion segment is composed of adjoining vertebrates, the lumbar disc, and adjoining ligaments between them, of which the endplate located between the vertebrae and the intervertebral disc, considered to be the most vulnerable structure[12]. It is obvious that both MCs and end plate defect is related to the lumbar degeneration. Therefore, it is considered that the lumbar sagittal malalignment may be a transitory stage in a lumbar degenerative process.

However, the role of lumbar sagittal alignment in the progression of Modic changes and endplate defects has not been illuminated. In the current study, we supposed that lumbar sagittal alignment patterns may be associated with the development of either Modic changes or endplate defects. Thus, we explored whether differences in sagittal parameters and especially spinopelvic parameters could predict the development of either Modic changes or endplate defects.

\section{Methods}

\section{Study Population}

This retrospective study enrolled 96 symptomatic or asymptomatic volunteers (age: mean 56, range 27-83; 44 males and 52 females) from August 2016 to December 2018. Written informed consent was got from all volunteers. This study was approved by the ethics board. All volunteers were 
diagnosed with low back pain and underwent an MRI examination according to standardized protocols. Exclusion criteria were: (1) history of lumbar surgery; (2) old vertebral body fracture; (3)abnormal bone metabolism including cancer, infection, and trauma; (4)high-grade spondylolisthesis. Inclusion criteria were: (1) age $\geq 25$ years; (2) suffered from chronic low back pain more than 3 months after conservative medication; (3) diagnosis confirmed by lumbar MRI. 76 patients diagnosed with MC\&ED were enrolled in the MC\&ED group and the rest 20 without MC\&ED were enrolled in a without MC\&ED group. Demographic data including age, gender, body mass index (BMI), smoking status, and Charlson comorbidity index (CCI) were collected.

\section{Lumbar sagittal parameters}

Sagittal and axial images were obtained on MRI scans from T12 upper endplate margin to S1 lower endplate margin. The measurements of the lumbar and pelvis sagittal parameters were: (1) lumbar lordosis (LL), LL was measured from the L1 superior endplate to S1 superior; (2)pelvic incidence (PI): the angle between the line perpendicular to the sacral plate and the line connecting the midpoint of the sacral plate to the bicoxofemoral axis; (3) sacral slope (SS): the angle between the S1 superior endplate and a horizontal line; (4) pelvic tilt (PT): the angle between a vertical line originating at the center of the bicoxofemoral axis and a line drawn between the same point and the middle of the superior endplate of S1; (5)lumbar lordosis index (LLI) is equal to $L L$ divided by $\mathrm{Pl} ;(6)$ idea $\mathrm{LL}=(\mathrm{PI} \times 0.5481+12.7) \times 1.087+21.61$, Loss of $\mathrm{LL}=$ idea $\mathrm{LL}-\mathrm{LL}$. (Fig. 1$)$

\section{Assessment of endplate defects}

The loss or disruption of the complete appearance was defined as endplate defects. Change of endplate defects visible on sagittal MR images was categorized into three grades according to Feng et al[13].Type 1 endplate defect, focal end plate defect, was observed as a discontinuity orhollow on the endplate. Type 2endplate defect, corner endplate defect, was observed as a legible corner on the endplate. Type 3 endplate defect, erosive endplate defect, observed as the extensivelyirregular, serrated, or worm-eaten appearance[14].Inter-rater agreement for the coding of endplate defect was calculated using Cohen's weighted kappa and Pearson's correlation.

\section{Assessment of MCs}

MCs were categorized into type 0 , I, II and III using sagittal multi-positional MRI image. Type 0 MCs showed normal endplate, type I MCs showed low T1 and high T2 signal, type II MCs showed high T1 and T2 signals, and type III MCs showed low T1 and T2 signals.

\section{Statistical analysis}

All statistical analyses were performed using SPSS (version, 21.0 SPSS Inc, Chicago, IL). Demographic characteristics were expressed as means \pm standard deviations $(\mathrm{x} \pm \mathrm{s})$ for continuous variables. Categorical variables were expressed as proportions and percentages. Mann-Whitney $\mathrm{U}$ test or chisquare test was used to compare parameters between groups. Moreover, Pearson correlation and linear regression analysis were also performed to analyze the relationship between lumbar sagittal alignment and the clinicaloutcomes. P less than 0.05 is considered statistically significant.

\section{Results}

\section{Demographics details}

Distribution of demographic variables such as age, weight, smoking status, and duration of symptoms in the two groups was significantly different ( $\mathrm{P}>$ 0.05); there was no significant difference in gender and $\mathrm{BMI}(P<0.05)$. Moreover, Modic changes and or end plate defects was observed in $79.16 \%$ of volunteers in group $A(76 / 96)$, and in $20.83 \bigotimes$ of volunteers in group $B(20 / 96)$, indicating no statistical difference in occurrence among groups.(Table 1 ) 
Table 1

Demographics details of the with/without MCs or end plate defect

\begin{tabular}{|llll|}
\hline \multicolumn{5}{c}{ groups } & With MC\&ED & Without MC\&ED & P-value \\
\hline Parameter & 76 & 20 & \\
Mean age (years) & $57.25 \pm 14.02$ & $49.7 \pm 10.25$ & $<0.05$ \\
\hline Gender & & & $>0.05$ \\
\hline Male & 34 & 10 & \\
Female & 42 & 10 & \\
\hline Body weight (kg) & $67.15 \pm 10.81$ & $68.45 \pm 7.91$ & $>0.05$ \\
\hline Height (cm) & $166.07 \pm 7.56$ & $164.80 \pm 8.35$ & $>0.05$ \\
\hline BMl (kg/m2) & & & $<0.05$ \\
\hline$<30$ & 13 & 6 & $>0.05$ \\
\hline$>30$ & 63 & 14 & $>0.05$ \\
\hline smoking consumption & 17 & 5 & $>0.05$ \\
\hline Alcoholconsumption & 23 & 6 & \\
\hline CCl & $2.11 \pm 0.89$ & $2.87 \pm 1.04$ & \\
\hline
\end{tabular}

\section{Lumbar sagittal parameters}

We further compared several lumbar sagittal parametersbetween bothgroups. $\mathrm{Pl}$ in group $\mathrm{A}$ was $51.46^{\circ} \pm 10.29^{\circ}$ and in group $\mathrm{B}$ was $49.7^{\circ} \pm 10.26^{\circ}(P>$ $0.05)$. $P T$ in group $A$ was $17^{\circ} \pm 6.97^{\circ}$ and in group $B$ was $16.9^{\circ} \pm 6.9^{\circ}(P>0.05)$. SS in group $A$ was $34.48^{\circ} \pm 8.07^{\circ}$ and in group $B$ was $32.81^{\circ} \pm 8.35^{\circ}(P<$ $0.05)$. LLin group $A$ was $40.50^{\circ} \pm 11.20^{\circ}$ and in group $B$ was $37.90^{\circ} \pm 10.43^{\circ}(P<0.05)$. LLI in group $A$ was $0.79 \pm 0.17$ and in group $B$ was $0.77 \pm 0.20(P<$ $0.05)$. Lossof $L L$ in group $A$ was $25.59^{\circ} \pm 8.77^{\circ}$ and in the group, $B$ was $27.12^{\circ} \pm 8.61^{\circ}(P<0.05)$. (Table 2$)$

Table 2

Comparison of the lumbar sagittal alignmentbetween the with MCs or endplate defect and without MCs or endplate defect groups

\begin{tabular}{|llll|}
\hline Parameter & withMC\&ED & withoutMC\&ED & P-value \\
\hline PI & $51.46 \pm 10.29$ & $49.7 \pm 10.26$ & $>0.05$ \\
\hline PT & $17 \pm 6.97$ & $16.9 \pm 6.9$ & $>0.05$ \\
\hline LL & $34.48 \pm 8.07$ & $32.81 \pm 8.35$ & $<0.05$ \\
\hline LLI & $40.50 \pm 11.20$ & $37.90 \pm 10.43$ & $<0.05$ \\
\hline Lossof LL & $25.59 \pm 8.77$ & $27.12 \pm 8.61$ & $>0.05$ \\
\hline
\end{tabular}

\section{Clinical outcomes}

The postoperative VAS and ODI scores at 3, 6, 12 and 24 months differed significantly from preoperative scores in two groups $(P<0.05)$. However, 24month postoperative VAS and ODI scores demonstrated improvement in the with Modic or endplate defect group compared with the without Modic or endplate defect group. VAS and ODI scores decreased at 3 and 6 months postoperative and then fell back slightly at 12 and 24 months postoperative( $P$ $<0.05$; Table 3). 
Table 3

clinical outcomes before and after surgery

\begin{tabular}{|c|c|c|}
\hline Time & VAS score & ODI score \\
\hline \multicolumn{3}{|c|}{ With MCs or end plate defect } \\
\hline Presurgery & $5.74 \pm 4.55^{\star}$ & $24.12 \pm 2.62^{\star}$ \\
\hline 3 months postsurgery & $2.88 \pm 2.55^{\star}$ & $21.47 \pm 3.31 *$ \\
\hline 6 months postsurgery & $2.25 \pm 2.36^{\star}$ & $17.03 \pm 3.46^{\star}$ \\
\hline 12 monthspostsurgery & $2.71 \pm 2.45^{\star}$ & $11.25 \pm 1.61^{\star}$ \\
\hline 24 months postsurgery & $3.43 \pm 1.31 *$ & $14.93 \pm 1.86^{*}$ \\
\hline \multicolumn{3}{|c|}{ withoutMCsorendplatedefect } \\
\hline Presurgery & $4.84 \pm 4.77$ *十 & $21.43 \pm 2.25^{\star}+$ \\
\hline 3 months postsurgery & $2.53 \pm 2.43$ *十 & $19.47 \pm 2.62^{\star}+$ \\
\hline 6 months postsurgery & $1.78 \pm 1.89 *+$ & $13.03 \pm 2.76^{\star}+$ \\
\hline 12 monthspostsurgery & $2.54 \pm 2.45$ *十 & $10.75 \pm 1.32 *+$ \\
\hline 24 months postsurgery & $3.02 \pm 2.26$ *十 & $12.93 \pm 2.02 *+$ \\
\hline
\end{tabular}


Table 4

Spearman's rank correlation coefficients between the lumbar sagittal parameters and clinical outcomes

\begin{tabular}{|c|c|c|c|c|c|c|c|c|c|c|c|c|c|c|}
\hline & & $\mathrm{PI}$ & PT & SS & LL & LLI & $\begin{array}{l}\text { Loss of } \\
\text { LL }\end{array}$ & Level 1 & $\begin{array}{l}\text { Level } \\
2\end{array}$ & Level 3 & Level 4 & Level 5 & $\begin{array}{l}\text { Level } \\
\text { S1 }\end{array}$ & ED \\
\hline \multirow[t]{2}{*}{$\mathrm{PI}$} & $\mathrm{R}$ & 1 & $0.577 * \star$ & $0.734^{\star \star}$ & $0.603 * *$ & -0.140 & -0.092 & 0.163 & 0.096 & 0.019 & $0.249 *$ & -0.025 & -0.179 & -0.074 \\
\hline & $P$ & & 0.000 & 0.000 & 0.000 & 0.174 & 0.375 & 0.113 & 0.352 & 0.855 & 0.014 & 0.805 & 0.080 & 0.473 \\
\hline \multirow[t]{2}{*}{ PT } & $\mathrm{R}$ & & 1 & -0.054 & -0.121 & $-0.734 \star \star$ & $0.592^{* \star}$ & -0.029 & -0.055 & 0.038 & $0.202^{\star}$ & 0.080 & -0.134 & 0.055 \\
\hline & $P$ & & & 0.599 & 0.242 & 0.000 & 0.000 & 0.780 & 0.597 & 0.711 & 0.048 & 0.441 & 0.194 & 0.591 \\
\hline \multirow[t]{2}{*}{ SS } & $\mathrm{R}$ & & & 1 & 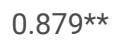 & $0.397 * \star$ & $-0.583^{\star \star}$ & 0.199 & 0.136 & 0.003 & 0.172 & -0.070 & -0.102 & -0.129 \\
\hline & $\mathrm{P}$ & & & & 0.000 & 0.000 & 0.000 & 0.052 & 0.185 & 0.977 & 0.094 & 0.501 & 0.322 & 0.210 \\
\hline \multirow[t]{2}{*}{ LL } & $\mathrm{R}$ & & & & 1 & $0.658 * *$ & $-0.816^{\star \star}$ & $0.281 * \star$ & 0.119 & -0.047 & 0.102 & -0.005 & -0.126 & -0.125 \\
\hline & $P$ & & & & & 0.000 & 0.000 & 0.005 & 0.247 & 0.652 & 0.322 & 0.958 & 0.222 & 0.226 \\
\hline \multirow[t]{2}{*}{ LLI } & $\mathrm{R}$ & & & & & 1 & $-0.958 \star \star$ & 0.230 * & 0.078 & -0.057 & -0.136 & 0.005 & 0.005 & -0.103 \\
\hline & $P$ & & & & & & 0.000 & 0.024 & 0.451 & 0.584 & 0.187 & 0.964 & 0.962 & 0.319 \\
\hline \multirow{2}{*}{$\begin{array}{l}\text { Loss } \\
\text { of LL }\end{array}$} & $\mathrm{R}$ & & & & & & 1 & $-0.284^{\star \star}$ & -0.119 & 0.051 & 0.073 & 0.020 & 0.024 & 0.093 \\
\hline & $P$ & & & & & & & 0.005 & 0.247 & 0.619 & 0.481 & 0.849 & 0.817 & 0.369 \\
\hline \multirow{2}{*}{$\begin{array}{l}\text { Level } \\
1\end{array}$} & $\mathrm{R}$ & & & & & & & 1 & $0.257 *$ & 0.025 & -0.074 & -0.025 & -0.004 & -0.051 \\
\hline & $\mathrm{P}$ & & & & & & & & 0.011 & 0.810 & 0.471 & 0.810 & 0.972 & 0.618 \\
\hline \multirow{2}{*}{$\begin{array}{l}\text { Level } \\
\text {. }\end{array}$} & $\mathrm{R}$ & & & & & & & & 1 & $0.358^{\star \star}$ & 0.192 & -0.024 & 0.035 & 0.105 \\
\hline & $P$ & & & & & & & & & 0.000 & 0.061 & 0.814 & 0.738 & 0.310 \\
\hline \multirow{2}{*}{$\begin{array}{l}\text { Level } \\
3\end{array}$} & $\mathrm{R}$ & & & & & & & & & 1 & $0.359 * \star$ & 0.016 & -0.159 & $0.205^{\star}$ \\
\hline & $\mathrm{P}$ & & & & & & & & & & 0.000 & 0.876 & 0.122 & 0.045 \\
\hline \multirow{2}{*}{$\begin{array}{l}\text { Level } \\
4\end{array}$} & $\mathrm{R}$ & & & & & & & & & & 1 & $0.279 \star \star$ & -0.170 & 0.217 * \\
\hline & $P$ & & & & & & & & & & & 0.006 & 0.097 & 0.034 \\
\hline \multirow{2}{*}{$\begin{array}{l}\text { Level } \\
5\end{array}$} & $\mathrm{R}$ & & & & & & & & & & & 1 & $0.367^{\star \star}$ & 0.160 \\
\hline & $\mathrm{P}$ & & & & & & & & & & & & 0.000 & 0.119 \\
\hline \multirow{2}{*}{$\begin{array}{l}\text { Level } \\
\text { S1 }\end{array}$} & $\mathrm{R}$ & & & & & & & & & & & & 1 & 0.049 \\
\hline & $\mathrm{P}$ & & & & & & & & & & & & & 0.639 \\
\hline \multirow[t]{2}{*}{ ED } & $\mathrm{R}$ & & & & & & & & & & & & & 1 \\
\hline & $P$ & & & & & & & & & & & & & \\
\hline \multicolumn{15}{|c|}{ 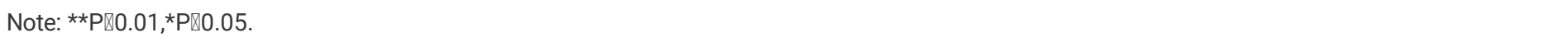 } \\
\hline
\end{tabular}

\section{Discussion}

In this study, we showed two novel findings. First, patients with improper lumbar sagittal alignment had a higher occurrence of Modic and endplate defect.

Previous studies regarding sagittal balance have demonstrated that lumbar malalignment after spine surgery may cause poor clinical outcomes[15, 16]. patients should be provided proper correction of the spinal alignment in order to prevent complications to occur. However, there is no studies focus attention on the effect of lumbar sagittal alignment in the progression of Modic changes and endplate defects before surgery until now. Thus, we conducted a study that mainly focused on the effect of lumbar sagittal alignment on the occurrence of Modic changes and endplate defects.

We think that the mechanism regarding the association between lumbar sagittal alignment and Modic changes or endplate defects is multifaceted. The lumbar segment with MCs or end plate defects tends to lumbar disk degeneration, the latter of which destabilizes the lumbar spine in turns and ultimately formed a vicious cycle. Moreover, the vertebral endplate fulfills the critical function of disc nutrient transport. MCs decrease nutrition transmit ability of endplate, infection factors serving as initial pathogenesis. In addition, morphological changes such as fatty infiltration or change in crosssectional area of lumbar muscles were observed in patients with low back pain. Patients with low back pain demonstrate a significantly higher 
prevalence of MCs and endplate defect with an unclear mechanism. We hypothesize that the change of lumbar sagittal alignment leads to lumbar muscles of these MCs patients fail to support spinal stability and finally led to fatty infiltration or change in cross-sectional area of lumbar muscles.

The unstable lumbar spine is able to enlarge the range of movement, which accelerates the degeneration of end plate and lumbar disc. Finally, the interaction between the two makes the disease to develop into a serious direction. In this study lumbar sagittal parameter was measured in patients with low back pain and we found that lumbar sagittal parameter in volunteers with MCs or end plate defect was larger than those in subjects without MCs orendplatedefect. A significant correlation between lumbar sagittal parameter, MCs, andendplatedefectwasfoundinlogistic regression analysis. We speculated that increased lumbarsagittalalignmentcould increase lateral shear force, leadingto the destroyed structure of endplate and formation of MCs.

In terms of the Modic and endplate defect, the prevalence of Modic changes and endplate defect was 79.16\% (76/96) in with Modic and endplate defect group and 20.83\% (20/96) in without Modic and endplate defect group. Meanwhile, differences in the presurgical lumbar sagittal alignment were observed in two groups. Thus, we hypothesize that presurgical lumbar sagittal alignment, measured by PI, PT, SS, LL, and PI-LL, was related to the incidence of Modic and endplate defect in symptomatic subjects.

In terms of the lumbar parameters, the results indicated that PT, SS, and PI-LL in the without Modic and endplate defect group were significantly higher than those in the Modic and endplate defect group, whereas LLI and loss of LLI in both groups demonstrated no significant difference. To the author's knowledge, no previous literature focuses attention on the relationship between lumbar sagittal alignment and without Modic and endplate defect. It is generally accepted that physiological cervical sagittal balance is important for normal spine function, and the maintenance of and improvements to cervical spine function are bound to have an effect on clinical efficacy and outcomes. As a result, Modic changes and endplate defect may be caused by malalignment of the lumbar spine. However, previous studies emphasized that there exist a relationship between sagittal alignment and degenerative changes only in the cervical spine[17]. In terms of the lumbarspine, Baron et alshowedthatspinopelvic sagittal alignment plays a predisposingrole in the pathogenesis of lumbar degeneration[18].

Even though we couldn't confirm whether these characteristics were the effect or the predictor of lumbar degeneration in the current retrospective study, they have potential clinical implications. Lumbar sagittal alignment plays a crucial role in predicting the development of Modic changes and endplate defects in symptomatic patients. Meanwhile, in the corrective surgery for patients with lumbar deformity, emphasis should be placed on the reconstruction of the lumbar sagittal alignment. Furthermore, lower lumbar muscles dystrophy because of a surgical exposure can contribute to postoperative deformities. Li et al reported that there is a correlation between spinopelvic alignment and degeneration of lower lumbar paraspinal muscles in elderly patients in a recent study[19]. Hence, the paraspinal muscle-strengthening exercises of lower lumbar levels could slow the progression of Modic changes and endplate defects. Longitudinal studies with subject outcomes need to be performed to validate our hypotheses.

Several limitations existed in this study. First, bias could not be avoided due to the nature of retrospective studies. Second, the study mainly focused on preoperative lumbar sagittal alignment and prevalence of Modic changes and endplate defects and not postoperative lumbar alignment or changes in lumbar alignment. Third, a high standard deviation of lumbar sagittal parameters reflects the flexibility of the lumbar spine. Thus, we should determine the reproducibility of lumbar sagittal parameters in further research.In addition, the lack of patient medical records made it difficult to verify the differences in clinical scores between patients with the imbalance and normal balance.

\title{
Conclusion
}

Lumbar sagittal alignment is a good predictor of the development of Modic changes and endplate defects for the association between them. Hence, maintaining a proper lumbar sagittal alignment was important in lumbar surgery, which seems to actas a vital role in the improved clinical outcomes.

\section{Abbreviations}

\author{
MC\&ED \\ Modic changes and end plate defect. \\ LL \\ Lumbar lordosis. \\ $\mathrm{Pl}$ \\ Pelvic incidence. \\ SS \\ Sacral slope. \\ PT \\ Pelvic tilt.
}

\section{Declarations}

\section{Ethics approval and consent to participate}

The study was approved by the Ethics Board of People' Hospital, Ningbo University 
(No. 2016LCSY17), and performed in accordance with the ethical standards laid down in the 1964

Declaration of Helsinki and its later amendments or comparable ethical standards. All individual

participants had written the informed consent.

\section{Availability of data and materials' statement}

The datasets used and analysed during the current study are available from the corresponding

author on reasonable request.

\section{Competing interests}

The authors declare that they have no competing interests.

\section{Funding}

This work was not supported by any fund or institution except People' Hospital, Ningbo University.

\section{Authors' contributions}

XXP and GC designed the work and was a major contributor in writing the manuscript. CCW, TY, WFS and

WYS performed data acquisition. GC and CCW undertook the analysis. All authors read and approved the final

manuscript.

\section{Acknowledgements}

Not applicable.

\section{References}

1. Wang Y, Videman T, Battie MC. Modic changes: prevalence, distribution patterns, and association with age in white men. Spine J. 2012;12(5):4116.

2. Paholpak P, Dedeogullari E, Lee C, Tamai K, Barkoh K. Sessumpun K, et al.

3. Do modic changes, disc degeneration, translation and angular motion affect facet osteoarthritis of the lumbar spine. Eur J Radiol. $2018 ; 98$ : 193 99.

4. Modic MT, Steinberg PM, Ross JS, Masaryk TJ, Carter JR. Degenerative disk disease: assessment of changes in vertebral body marrow with MR imaging. Radiology. 1988;166(1 Pt 1):193-9.

5. Imaging of degenerative disk disease

Modic MT, Masaryk TJ, Ross JS, Carter JR. Imaging of degenerative disk disease.

6. Radiology. 1988;168(1): $177-86$.

7. Maatta JH, Karppinen JI, Luk KD, Cheung KM, Samartzis D. Phenotype profiling of Modic changes of the lumbar spine and its association with other MRI phenotypes: a large-scale population-based study. Spine J. 2015;15(9):1933-42.

8. Mok FP, Samartzis D, Karppinen J, Fong DY, Luk KD, Cheung KM. Modic changes of the lumbar spine: prevalence, risk factors, and association with disc degeneration and low back pain in a large-scale population-based cohort. Spine J. 2016;16(1):32-41.

9. Samartzis D Multidimensional vertebral

Zehra U, Cheung JPY, Bow C, Lu W. Samartzis D. Multidimensional vertebral.

10. endplate defects are. associated with disc degeneration, modic changes, facet joint abnormalities, and pain. J Orthop Res. 2018;37(5):1080-89.

11. Rade M, Maatta JH, Freidin MB, Airaksinen O, Karppinen J, Williams FMK. Vertebral Endplate Defect as Initiating Factor in Intervertebral Disc Degeneration: Strong Association Between Endplate Defect and Disc Degeneration in the General Population. Spine. 2018;43(6):412-19.

12. Sagittal alignment assessment after Vazifehdan F, Karantzoulis VG, Igoumenou VG. Sagittal alignment assessment after.

13. short-segment lumbar. fusion for degenerative disc disease. Int Orthop. 2018;43(4):891-8.

14. Buckland AJ, Ramchandran S, Day L, Bess S, Protopsaltis T, Passias PG, et al. Radiological lumbar stenosis severity predicts worsening sagittal malalignment on full-body standing stereoradiographs. Spine J. 2017;17(11):1601-10.

15. Ogura Y, Shinozaki Y, Kobayashi Y, Kitagawa T, Yonezawa Y, Takahashi Y, et al. Impact of sagittal spinopelvic alignment on clinical outcomes and health-related quality of life after decompression surgery without fusion for lumbar spinal stenosis. J Neurosurg Spine. 2019.

Page $8 / 10$ 
DOI:10.3171/2018.10.SPINE181094.

16. Vertebral fractures usually affect

Zhao FD, Pollintine P, Hole BD, Adams MA, Dolan P. Vertebral fractures usually affect.

17. the cranial endplate. because it is thinner and supported by less-dense trabecular bone.

18. Bone. 2009; 44(2): 372-9.

19. Feng Z, Liu Y, Yang G, Battie MC, Wang Y. Lumbar Vertebral Endplate Defects on Magnetic Resonance Images: Classification, Distribution Patterns, and Associations.

20. with Modic Changes and Disc Degeneration. Spine. 2018;43(13):919-27.

21. Zehra U, Cheung JPY, Bow C, Lu W, Samartzis D. Multidimensional vertebral endplate defects are associated with disc degeneration, Modic changes, facet joint abnormalities and pain. J Orthop Res. 2018;37(5):1080-9.

22. Cho JH, Joo YS, Lim C, Hwang CJ, Lee DH, Lee CS. Effect of one- or two-level posterior lumbar interbody fusion on global sagittal balance. Spine J. 2017;17(12):1794-802.

23. Farrokhi MR, Yadollahikhales G, Gholami M, Mousavi SR, Mesbahi AR, Asadi-Pooya AA. Clinical Outcomes of Posterolateral Fusion vs. Posterior Lumbar Interbody Fusion in Patients with Lumbar Spinal Stenosis and Degenerative Instability. Pain Physician. 2018;21(4):383-406.

24. Tamai K, Romanu J, Grisdela P, Paholpak P, Zheng P, Nakamura H, et al. Small C7-T1 lordotic angle and muscle degeneration at C7 level were independent radiological characteristics of patients with cervical imbalance: a propensity score-matched analysis. Spine J. 2018;18(9):1505-12.

25. Garcia-Ramos CL Zarate-Kalfopulos B, Reyes-Tarrago F, Navarro-Aceves LA. Garcia-Ramos CL.

26. Reyes-Sanchez AA, Alpizar-Aguirre A, et al. Characteristics of Spinopelvic Sagittal Alignment in Lumbar Degenerative Disease. World Neurosurg. 2019;126:e417-21.

27. Li Q, Sun J, Cui X, Jiang Z, Li T. Analysis of correlation between degeneration of lower lumbar paraspinal muscles and spinopelvic alignment in patients with osteoporotic vertebral compression fracture. J Back Musculoskelet Rehabil. 2017;30(6):1209-14.

\section{Figures}

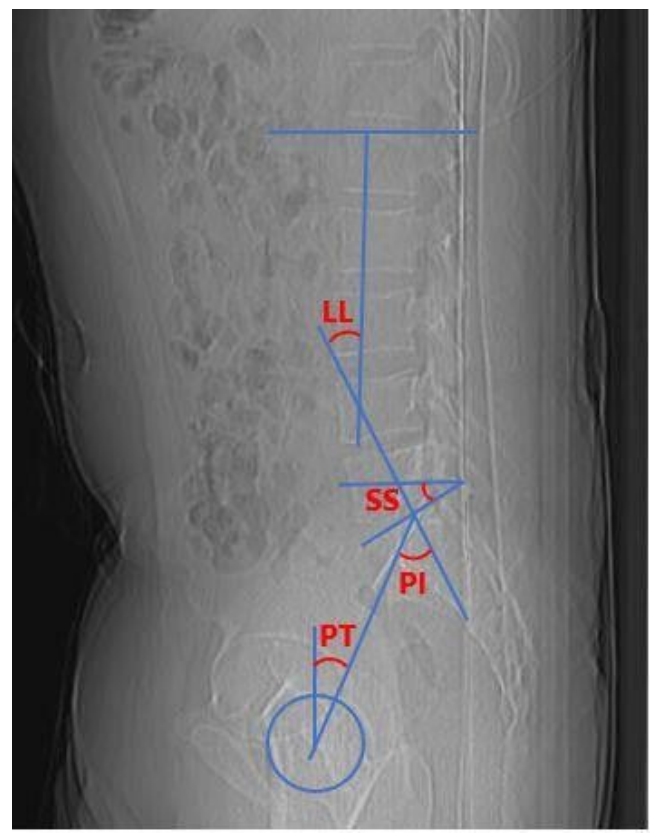

\section{Figure 1}

The lumbarsagittal alignment of thelumbar spine 

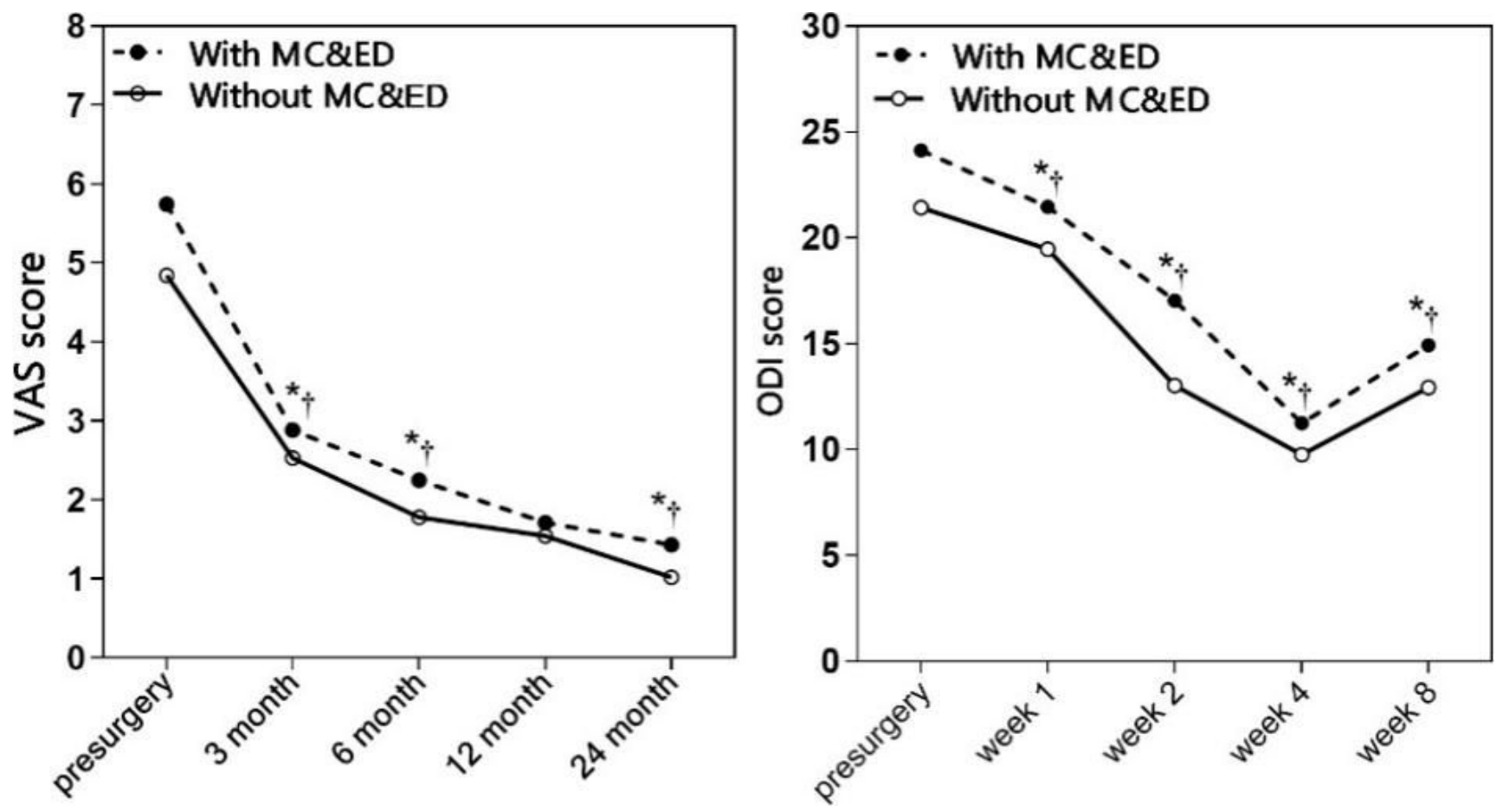

Figure 2

VAS and ODI scores before and after surgery 